\title{
nature
}

nanotechnology

\section{Combating climate change}

\author{
Last month a government department in the UK issued a press release that asked \\ "Can nanoscience help in the fight against climate change?" The answer is a cautious yes.
}

Rarely a week goes by without a major announcement about climate change. Slowly but surely politicians are realizing that the world needs to do something to reduce emissions of greenhouse gases, otherwise the consequences for our planet could be catastrophic. Add to this growing fears in many countries about security of supply - be it for oil from the middle east or gas from Russia - and increasing demand from China, India and other rapidly developing economies, and the case for other non-polluting sources of energy becomes overwhelming. But what has this got to do with nanotechnology? Quite a lot as it happens.

There is no single solution to the challenge of reducing greenhouse-gas emissions and combating climate change. Reducing demand, increasing efficiency and developing low-carbon forms of energy will all be necessary. There is not much nanotechnology can do to reduce demandif people want to drive everywhere or watch 48-inch television screens, science cannot stop them. However, nanotechnology can - in concert with many other technologies - help to improve efficiency and bring new energy sources to the market. This represents an enormous opportunity for the international nanoscience and technology community.

So how can nanotechnology help? A recent report ${ }^{1}$ commissioned by the Department for Environment, Food and Rural Affairs in the UK begins to answer this question, listing five areas where nanotechnology can make a difference: fuel additives to increase the efficiency of diesel engines; photovoltaic technology for solar cells; the hydrogen economy and fuel cells; batteries and supercapacitors for energy storage; and improved insulation for houses and offices. The consultants who wrote the report, Oakdene Hollins, whittled down a longer list to identify these five priority areas based on three criteria: distance to market, competition from alternative technologies, and the infrastructural changes need to implement the new technology. The report follows hard on the heels of a US report on green nanotechnology, which discussed ways in which all nanotechnologies - not just those connected with energy - could be made more environmentally friendly ${ }^{2,3}$.

\section{Nanoparticles are already used to increase fuel efficiency.}

The nanotechnology with the potential to have the biggest impact on greenhousegas emission in the shortest period of time is fuel additives. Nanoparticles are already used to increase the fuel efficiency of buses, although this technology is currently the subject of a dispute about patents ${ }^{4}$. The report estimates that such additives could result in a saving of up 2-3 million tonnes of carbon dioxide per year in the UK. An added bonus is that other harmful emissions would also be reduced. (Nanotechnology is also reducing emissions elsewhere in the oil industry: for instance, molybdenum disulphide nanocrystals are used as catalysts to remove potentially harmful sulphur compounds from crude $\mathrm{oil}^{5}$.) However, before nanoparticle fuel additives can realize their full potential, it will be necessary to show that they do not have an adverse impact on human health or the environment. And solving some of the challenges related to the other priority areas - such as introducing the infrastructure needed for the hydrogen economy - will require much more than research alone.

From the viewpoint of the nanoscience and technology community, the specific recommendations in the report are less important than the way it highlights the potential for nanotechnology to make a real impact on climate change. However, the different nanotechnologies that will be brought to bear on this problem will only form part of a much larger technologybased solution, which, in turn, will also be at the mercy of politics, economics and market forces. The bewildering economics of the electricity industry are highlighted by the fact that a joint venture $^{6}$ between the National Grid in the UK and TenneT in the Netherlands is about to spend $€ 600$ million on a $260 \mathrm{~km}$ long interconnector that will transmit power back and forth between the two countries "driven by price differentials and demand patterns between the two power markets". Electricity is big business and all the nascent nano-enabled energy technologies - fuel cells, advanced photovoltaics and so on - will have to fight to make an impact.

\footnotetext{
References

1. Environmentally Beneficial Nanotechnologies: Barriers and Opportunities (2007); available at www.defra.gov.uk/ environment/nanotech/policy/index.htm

2. Green Nanotechnology: It's Easier Than You Think (2007); available at nanotechproject.org

3. Nature Nanotech. 2, 257 (2007).

4. Nature 446, 963 (2007).

5. Lauritsen, J.V. \& Besenbacher, F. Adv. Catal. 50, 97-147 (2006) 6. www.nationalgrid.com/uk/Interconnectors/Netherlands/
} 